\title{
Cyberbullying and Traditional Bullying in Greece: An Empirical Study
}

\author{
Maria Papatsimouli ${ }^{1}$, Stavroula Tavoultzidou ${ }^{1}$, Vaggelis Saprikis ${ }^{2}$, Lazaros Lazaridis ${ }^{1}$, Eleni Michailidi ${ }^{1}$ \\ , Ioannis Skordas ${ }^{1}$, and George F. Fragulis ${ }^{1}$ \\ ${ }^{1}$ Laboratory of Robotics, Embedded and Integrated Systems, Dept. of Electrical and Computer Engineering, \\ University of Western Macedonia \\ ${ }^{2}$ Dept. Of Management Science \& Technology, University of Western Macedonia
}

\begin{abstract}
The use of Internet technology has changed the way people interact rendering face-to face and verbal communication a trend of the past. Thus, a new world has been created for young people, who send emails, visit websites, use webcams, chat rooms and instant messaging through social media for communication. As a result, a new type of bullying, cyber bullying has emerged. The present study aims to investigate the extent of cyber bullying in Greece in terms of: a) gender and cyber bullying, b) hours spent on line and cyber bullying, c) cyber bullying and traditional bullying victims and d) cyber bullying victims and family relations. The sample consisted of 466 participants, $27 \%$ of which $(\mathrm{N}=128)$ were less than 18 years old. A standardized questionnaire was formulated for data collection and Chisquare, statistical test was used to test the research hypotheses formulated. The results revealed significant theoretical and practical implications, as the majority of the research questions confirmed the relationship between cyber bullying and traditional bullying victims, as well as cyber bullying victims and family relations.
\end{abstract}

Keywords - Cyberbullying, traditional bullying, victims, adolescents, victimization, Bullies

\section{Introduction}

Bullying can be defined as an aggressive or intentional act or behaviour repeatedly committed against a victim unable to defend himself/herself [1],[2]. Taking the previous definition into account, cyber bullying, the evolution of bullying, as it is often referred to, could be defined as an aggressive or intentional act or behaviour repeatedly committed through an electronic contact form. The Internet is often referred as the new Wild West, the Wild West of the 21 st century, which has to be explored, as it provides excitement and adventure. However, as Wild West, Internet is full of dangers as well, and as Franek pointed out "We need to be sheriffs in this new Wild West - a cyberspace bombarding kids. As anyone who has ever been a victim of bullying and harassment will tell you, the bullets may not be real, but they can hurt" [3].

\section{Bullying}

Bullying is the victimization of a person repeatedly exposed to negative acts by one or more people [4]. A negative action, by definition of aggressive behaviour, when one deliberately causes or attempts to cause injury to another. In bullying, there is physical contact between the offender, i.e. bully, and the victim, during which negative actions are performed in words or in other ways, such as grimaces or ugly gestures, by spreading rumours or by deliberately excluding the victim from a group.

\subsection{Bullies aggressive reaction}

According to [5], there are four factors influencing bullies' aggressive reactions which could be the answers to the question "What kind of upbringing and what other conditions could contribute to the development of aggressive behaviour during childhood?" These factors could be the following:

1. The caretaker's emotional attitude, usually the mother's, towards the child during the early years of his/her life, i.e. lack of warmth and emotional involvement

2. A tolerant attitude from the caretaker which might enhance the child's aggressive behaviour. Caretakers should set boundaries when there is aggressive behaviour among peers, brothers and sisters, and other adults.

3. Power-assertive methods, such as physical punishment, often used by parents or caretakers or violent outbursts. These are more likely to influence a child behave more aggressively than an average child because in most cases "Violence begets violence".

4. Bad parenting image often characterised by aggressiveness, lack of love and care. Children even from their early days of life tend to observe and imitate everyone around them. Therefore, they learn to behave by copying their parents' /caretaker's behaviour and in their adult life, they are very likely to behave the same towards their children. 
A child with a "short-term" temperament will probably become more aggressive than another with a common temperament. We could argue therefore that a child with a bad parenting image and with no behaviour boundaries, is more prone to acquire aggressive behaviour. It should be mentioned however, that the family's socio-economic status does not necessarily relate to children's aggressive behaviour.

\section{Cyberbullying}

Cyber bullying is the evolution of traditional bullying, occurring through the use of electronic communication technologies, such as social media, e-mail, texting and messaging applications, online gaming, instant messaging, online chatting, online forums, chat rooms, message boards. Like bullying, it can occur in all countries, irrespective of the victim's culture and region of origin [6],[7]. Anonymity and privacy violations are traits that make cyber bullying more painful for the victims [8] . Thus, by using information and communication technologies, and especially the internet for the purpose of bullying or harassment, in online bullying we have personal privacy violations, difficulty in handling emails and anonymity. According to the UK National Bullying Helpline, Cyber bullying, i.e. Bullying and harassment using technology, involves various forms of online abuse, such as trolling, mobbing, stalking, and grooming, whereas there is an increasing trend, as more and more children and parents resort to reporting a variety of different cases every day. https://www.nationalbullyinghelpline.co.uk/cyberbullying.html

\subsection{Cyberbulling and parenting}

The role of parents in cyber bullying has not been thoroughly explored so far, because children usually keep their parents away, when it comes to using the internet, as they feel that their privacy is being violated [9]. In addition, children do not talk to their parents about their involvement in cyber bullying because of fear of punishment, loss of computer rights and isolation from their peers([10], [11], [8]). As a result, parents may be unaware whether their child has been a cyber bullying victim or a cyber bullying offender ([12], [13]). Studies have shown that children who have been cyber bullying offenders have had limited parental supervision, strict parents, i.e. parents using power-assertive methods such as physical punishment, while there also existed a weaker emotional bond between children and parents when compared to children who have not cyber bullied [14], [15]. Insufficient parenting also reduces the social competence of children, who might fail, for example, to develop positive friendships. In contrast, when there is parental supervision and emotional involvement, children's aggressive behaviour is reduced both within the family context, as well as in all other contexts [16], [17], [18]. The way a parent interacts with his/her child influences the child's interaction with others. If parents' interaction with their children is hostile and cold, children adopt the same way to interact with others.
This affects the child's socialization, while he/she is more likely to become a cyber bullying offender/ bully [19].

Antisocial behaviour is unlikely to occur in a child who has grown up with supervision, discipline and affection ([20], [21], [22], [23], [17], [24]). Many researchers have dealt with parental responsiveness and traditional bullying and found a negative correlation between the two. Thus, due to low parental responsiveness bullying behaviour and increased victimization may emerge. ([25], [26], [27]). Other researchers compared perpetrators and victims and concluded that perpetrators had experienced lower parental responsiveness than the victims([28], [29], [30]). However, both dimensions coexist and affect each other [21], [31], [32]. Figure 1, shows the four parenting styles and the combination of both dimensions results [13].

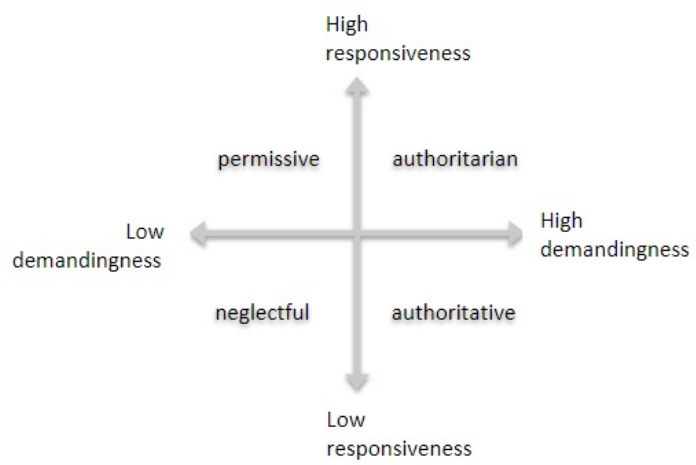

Figure 1. Parenting styles

Various studies have also been conducted examining the relationship between parenting styles and cyber bullying. The results showed that children with cyber bullying experiences had limited parental control, stricter parental discipline in their family context, and poorer emotional attachment to their parents, when compared to children who did not have cyber bullying experiences [14], [15] ,[33].

\subsection{Cyber Bullying and Anonymity}

According to [8] cyber bullying is more painful to victims than bullying, since it is characterized by anonymity, invasion of personal life and inability of the victim to hide from his/her torturers in the electronic world. Although anonymity is claimed to be one of the factors that differentiates cyber bullying from bullying, there have been only a few longitudinal studies that have investigated how and why anonymity affects cyberbullying behaviour [34]. Barlett in [35] investigated the effect of anonymity on cyber bullying frequency in an attempt to determine the variables predicting it, thus contributing to intervention efforts aimed at reducing cyber bullying. The results of his study showed that anonymity, cyber bullying reinforcement and positive attitudes toward cyber bullying strongly predicted cyber bullying frequency. In addition, moderation tests confirmed that high positive attitudes and anonymity result in high cyber bullying. Also mediation tests made clear 
that anonymity mediated the relation between instant messaging frequency and cyber bullying behaviour. Moore et al. [36] explored anonymity and roles associated with aggressive posts in an online forum. Having labeled forum posts automatically for aggression and anonymity and manually as attacks or defends of the forum owner, they found out aggression correlating with attacks and defends and anonymity correlating with attacks positively and defends negatively.

\subsection{Cyberbullying and Traditional Bullying}

Traditional Bullying and Cyber bullying have the same characteristics, i.e. repetition, expediency, power balance. In the case of cyber bullying, there is always the risk of misunderstanding. Thus, a joke can be misunderstood or interpreted as deliberate and evil. In addition, cybercriminals may be strangers in contrast to traditional bullying [13], [37], [38], [39], [40]. When compared to victims of traditional bullying, victims of cyber bullying will face difficulties in avoiding cyber bullying, as due to online communication they can be attacked anywhere and anytime [41]. Thus, while victims of traditional bullying may stop long-term bullying and temporarily take control of the situation, when they break negative contact with the bully, i.e. by leaving school and going home, or by speaking to a trustworthy adult, there seems to exist "no safe haven" for cyber bullying victims who often feel powerless and that they have lost control [42]. In addition, the fact that in traditional bullying the bully is known, by contrast to cyber bullying, differentiates the situation a lot, as cyber-victims may feel helpless seeing no way to escape.

\section{Research Questions}

The fact that the present survey is about Cyber-bullying in Greece, a topic that previous surveys have not dealt with, makes it particularly important. More particularly, the survey attempts to explore the following research questions:

1. What is the extent of cyber bullying in Greece?

2. Which gender is more vulnerable to bullying?

3. What is the relationship between the victims and their family?

4. Is cyber bullying related to the hours spent on the Internet?

5. Is there a correlation between victims of traditional bullying and victims of cyber bullying?

6. Is there a correlation between cyber bullying victims and perpetrators?

\section{Methodology}

This section presents the design of the survey, the instruments used, the participants and the data processing and analyzing techniques.

\subsection{Instruments}

For data collection an online questionnaire was designed, using Google forms, whereas the Olweus Bully / Victim Questionnaire [2], the Parenting Questionnaire and an adapted version of the Parenting Style Questionnaire [43] constituted the basis for questions development. The questions developed were closed-ended, Yes/ No questions and Likert scale questions [44]. The questionnaire consisted of six sections. The first section included demographic questions. In the second, there were questions about the use and the reasons of using the Internet. The third section involved questions about cyber bullying, i.e. what is cyber bullying, emotions, consequences and how to deal with it. The next section dealt with traditional bullying. In this section, respondents were asked to answer questions about traditional bullying concerning whether the victims could solve the problem and how. The fifth section concerned cyber bullying perpetrators. In this section, respondents were asked whether they had ever been perpetrators, and if yes for what reasons and in what way. Finally, in the sixth section there was a validation question to confirm that a person completed the questionnaire rather than a machine.

\subsection{Participants}

466 participants were recruited via email and social media. In order to ensure confidentiality, the questionnaires were completed anonymously [45]. 525 questionnaires were completed, whereas 466 of them were considered valid.

\subsection{Data Collection and Analysis}

For data collection, the primary data collection method and more particularly the quantitative data collection method, employing a standardized questionnaire with variations, was selected. Prior to the start of the survey, a pilot questionnaire was administered to 20 students who did not participate in the study. Thus, some questions were reviewed in order to become more clear and comprehensible with an aim to facilitate the participants answer correctly and with a greater ease. Data collection was done during March and April 2018. When all participants completed the survey, the scores were downloaded into the Statistical Package for the Social Sciences (SPSS) programme for analysis.

\section{Results}

\subsection{Demographic Questions}

\subsubsection{Gender Results}

Of the participants recruited $(\mathrm{N}=466), 60.5 \%(\mathrm{~N}=282)$ were female and $39.5 \%(\mathrm{~N}=184)$ were male.

\subsubsection{Age Results}

Most participants $41 \%(\mathrm{~N}=191)$ belonged to the $19-25$ years age group, followed by $27.5 \%(\mathrm{~N}=128)$ under 18 years, $11.4 \%(\mathrm{~N}=53)$ over 40 years, $8.2 \%(\mathrm{~N}=38)$ between $36-40$ years and $6.9 \%(\mathrm{~N}=32)$ between $26-30$ years. 


\subsubsection{Hours spent online results}

The majority of the participants spent 1-3 hours online. More particularly:

- 41.4\% ( $\mathrm{N}=193)$ spent 1-3 hours online

- $38.4 \%(\mathrm{~N}=179)$ spent 4-6 hours online

- $13.7 \%(\mathrm{~N}=64)$ spent 7-9 hours online

- $6.4 \%(\mathrm{~N}=30)$ spent more than 9 hours

\subsection{Cyber bullying victims' results}

\subsubsection{Gender and cyber bullying victims' results}

In order to investigate how many of the participants had ever been cyber bullying victims and which gender in particular was more vulnerable to cyber bullying, we used cross-tabulation in SPSS. Results indicated that $13.15 \%$ ( $\mathrm{N}=61)$ of the participants had been cyber bullying victims, of which, $29.5 \%(\mathrm{~N}=18)$ were male, whereas $70.5 \%$ $(\mathrm{N}=73)$ were female. We observe that the percentage of the female cyber bullying victims is twice as high as that of the male ones. It is obvious therefore, that women are more likely to be cyber bullying victims.

\subsubsection{Age and cyber bullying victims' results}

SPSS cross-tabulation was also used regarding the age of cyber bullying victims. Thus, it was shown that cyber bullying victims belonged to the following age groups:

- $50.8 \%,(\mathrm{~N}=31)$ to the $19-25$ age group

- $23 \%(\mathrm{~N}=14)$ to the under 18 years age group

- $9.7 \%(\mathrm{~N}=6)$ to the over 40 years age group

- $6.6 \%(\mathrm{~N}=4)$ to the $31-35$ age group

- $6.6 \%(\mathrm{~N}=4)$ to the 26-30 age group

- $3.3 \%(\mathrm{~N}=2)$ to the $36-40$ age group

We can conclude therefore that the 19-25 age group was the most vulnerable to cyber bullying, whereas the 36-40 age group the least vulnerable one.

\subsubsection{Cyber bullying victims and hours spent online results}

In order to explore whether cyber bullying was related to the hours spent on the Internet, SPSS cross-tabulation was used. Results showed that such a relationship might exist, as the majority of cyber bullying victims (41\%) spent 4-6 hours online.

\subsubsection{Dealing with cyber bullying results}

Answers to the question "Have you dealt successfully with cyber bullying?" revealed that the majority of the participants, i.e.78.7\% ( $\mathrm{N}=48)$ managed to deal successfully with cyber bullying, whereas $21.3 \%(\mathrm{~N}=13)$ failed to face the problem. For data analysis SPSS cross-tabulation was used.

\subsection{Cyber bullying and traditional bullying victims' results}

\subsubsection{Number of Cyber bullying and traditional bullying victims}

With a view to answer the research question whether there is a correlation between victims of traditional bullying and victims of cyber bullying, there was an attempt to identify the number of cyber bullying and traditional bullying victims. Thus, using SPSS cross-tabulation it was found that:

- $62.4 \%(\mathrm{~N}=291)$ of the participants had been neither cyber bullying, nor traditional bullying victims

- $24.5 \%(\mathrm{~N}=114)$ of the participants had never been cyber bullying victims, but they had been traditional bullying victims

- 7.1\% $(\mathrm{N}=33)$ of the participants had been both cyber bullying and traditional bullying victims

- $6 \%(\mathrm{~N}=28)$ of the participants had been cyber bullying victims, but they had never been traditional bullying victims

\subsubsection{Cyberbullying victims, traditional victims and bullies}

As shown in Figure 2, 31.5\% ( $\mathrm{N}=147)$ of the participants were traditional bullying victims, whereas only $13.1 \%$ $(\mathrm{N}=61)$ were cyber bullying victims. It is also worth pointing out that $5.4 \%$ of the participants bullied other people.

\begin{tabular}{|c|c|c|c|c|c|c|}
\hline & \multicolumn{2}{|c|}{ Cyberbullying victim } & $\begin{array}{c}\text { Traditional bullying } \\
\text { victim }\end{array}$ & \multicolumn{2}{|c|}{ Bully } \\
\hline & Frequency & Percent & Frequency & Percent & Frequency & Percent \\
\hline No & 405 & $86.9 \%$ & 319 & $68.5 \%$ & 441 & $94.6 \%$ \\
\hline Yes & 61 & $13.1 \%$ & 147 & $31.5 \%$ & 25 & $5.4 \%$ \\
\hline Total & 466 & $100 \%$ & 466 & $100 \%$ & 466 & $100 \%$ \\
\hline
\end{tabular}

Figure 2. Cyberbullying victims,traditional victims,and bullies

Therefore, it could be concluded that traditional bullying seems to be more common than cyber bullying in Greece.

\subsubsection{Cyber bullying victims and bullies}

According to Figure 2, 61 participants have been Cyber bullying victims and 8 participants have been bullying someone else too.

In Figures 3, 4 and 5, it is obvious that the significance value is lower than the "a" value $(0.004<0.05)$ and there is a statistical dependence between the variables on the level of significance $a=0.05$. Statistically significant dependence was identified and it is following the assessment of its intensity. For this reason, we used the causation coefficients Phi Cramer's V in order to compare the strength of the coefficient between the variables. Phi and Cramer's V 


\begin{tabular}{|c|c|c|c|c|c|}
\hline & & & $\begin{array}{c}\text { Have you ever } \\
\text { been a victim of } \\
\text { cyberbullying? }\end{array}$ & & Total \\
\hline & & No & Yes & \\
\hline $\begin{array}{c}\text { Have you ever } \\
\text { bullied other }\end{array}$ & No & Count & 388 & 53 & 441 \\
\hline nananlo? & & $\%$ of Total & 0.833 & 0.114 & 0.946 \\
\hline & Yes & Count & 17 & 8 & 25 \\
\hline & & $\%$ of Total & 0.036 & 0.017 & 0.054 \\
\hline \multicolumn{6}{|r}{} \\
\hline
\end{tabular}

Figure 3. Cyberbullying victims/bullies

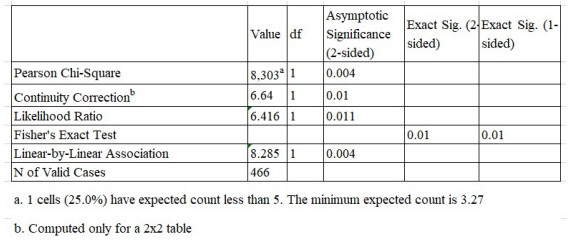

Figure 4. Chi-Square Tests

\begin{tabular}{|l|l|l|l|}
\hline \multicolumn{2}{|l|}{} & Value & $\begin{array}{l}\text { Approximate } \\
\text { Significance }\end{array}$ \\
\hline \multirow{2}{*}{ Nominal by Nominal } & Phi & 0.133 & 0.004 \\
\cline { 2 - 4 } & $\begin{array}{l}\text { Cramer's } \\
\text { V }\end{array}$ & 0.133 & 0.004 \\
\hline N of Valid Cases & 466 & \\
\hline
\end{tabular}

Figure 5. Symmetric Measures

are estimated factors of the intensity (size) of the connection between two quality variables. In the case of independence between the two variables, the value of the factors is close to zero (0). In our case, Phi Coefficient is 0.133 , thus pointing to a relationship between bullies and cyber bullying victims. Finally, in order to determine the existence of dependence between bullies and cyber bullying victims, the Chi-square test of independence was used to determine if there is a significant relationship between the two variables. Also, Phi and Cramer's V coefficients were calculated. According to the results, there is a significant relationship on the Level of significance $\mathrm{a}=0.05$ between bullies and cyber bullying victims $(\mathrm{x} 2=8.303$, sig $=0.004)$. As Phi dependence coefficient is 0.133 , there is a small dependence between bullies and cyber bullying victims.

\section{Cyberbullying victims and traditional bullying victims}

According to Figures 6, 7 and 8114 respondents have been traditional bullying victims and 28 respondents have been cyber bullying victims, whereas 33 have been both.We can see that the sig. value is lower than the "a" value $(0.000<0.05)$. According to this, the null hypothesis is rejected and there is a statistical dependence between the variables on the level of significance $a=0.05$ :

Statistically, significant dependence was identified and it is following the assessment of its intensity. For this reason, we are using the causation coefficients Phi Cramer's

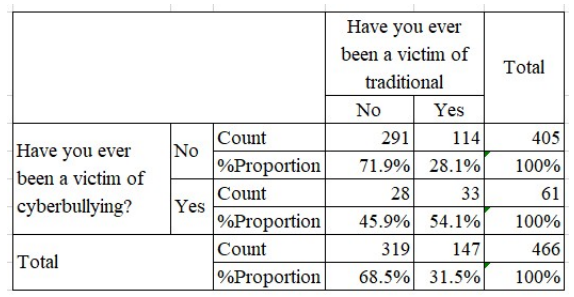

Figure 6. Traditional and cyber bullying Cross-tabulation

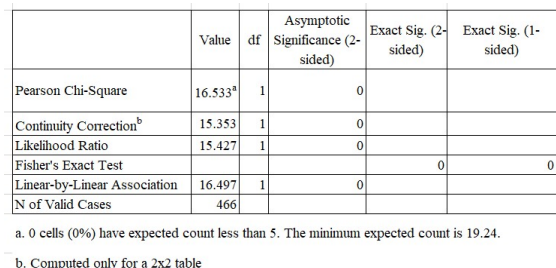

Figure 7. Traditional and cyber bullying Chi-Square Tests

\begin{tabular}{|l|l|r|r|}
\hline \multicolumn{2}{|l|}{} & Value & $\begin{array}{l}\text { Approximate } \\
\text { Significance }\end{array}$ \\
\hline $\begin{array}{l}\text { Nominal } \\
\text { by } \\
\text { Nominal }\end{array}$ & $\begin{array}{l}\text { Cramer's } \\
\text { V }\end{array}$ & 0.188 & 0 \\
\hline \multicolumn{2}{|l|}{ N of Valid Cases } & 466 & 0 \\
\hline
\end{tabular}

Figure 8. Symmetric Measures

$\mathrm{V}$ in order to compare the strength of the coefficient between the variables. Phi Coefficient is 0.188 and meaning that there is a relationship between traditional bullying victims and cyber bullying victims. Finally, for determining the existence of dependence between traditional bullying victims and cyber bullying victims, the Chi-square test of independence was used to determine if there is a significant relationship between the two variables. Also, Phi and Cramer's V coefficients were calculated. According to the results, there is a significant relationship in the Level of significance $\mathrm{a}=0.05$ between bullies and cyber bullying victims $\left(x^{2}=16.533\right.$, sig. $\left.=0.004\right)$. As Phi dependence coefficient is 0.188 , there is a small dependence between bullies and cyber bullying victims. According to Figures 9 and 10, Sig value of the Levene's Test for Equality of Variances is $0.139(>0.05)$ and Sig. (2-tailed) value is 0.002 $(<0.05)$. This means that there is a correlation between cyber bullying victims and family relations.

\begin{tabular}{|c|l|r|r|r|r|}
\hline & $\begin{array}{l}\text { Have you ever } \\
\text { been a victim of } \\
\text { cyberbullying? }\end{array}$ & N & Mean & $\begin{array}{c}\text { Stc. } \\
\text { Deviation }\end{array}$ & $\begin{array}{c}\text { Std. } \\
\text { Error } \\
\text { Mean }\end{array}$ \\
\hline $\begin{array}{c}\text { How would you describe } \\
\text { your relationship with your } \\
\text { family? }\end{array}$ & Yes & 405 & 4.42 & 0.813 & 0.04 \\
\hline
\end{tabular}

Figure 9. Group Statistics 


\section{Conclusions}

Cyber bullying, cyber harassment or on line bullying is the evolution of traditional bullying, which takes place over electronic means. Technology advances have made it a rather common phenomenon, mainly among adolescents, who have access to electronic devices from a very early age. Thus, although there is a worldwide trend to combat cyber bullying and support cyber bullying victims through intervention efforts, international campaigns, legislative actions, there seems to be a long way ahead to stop cyber bullying. In the present study there has been an attempt to explore the extent of cyber bulling in Greece. For data collection an online questionnaire was designed, whereas participants were recruited via email and social media. Data analysis was done by the SPSS statistical programme. The main research findings could be summarized as follows:

- Cyber bullying seems to have a small extent in Greece, when compared to traditional bullying, which seems to be more common

- Girls are likely to be more vulnerable to cyber bullying

- Cyber bullying victims spend 4-6 hours online

- There is a statistical dependence between cyber bullying and traditional bullying victims

- There is a correlation between cyber bullying victims and family relations

However, results also point to the need for a broader investigation of cyber bullying in Greece, as cyber bullying is an evolving phenomenon closely relating to technology, which is continuously evolving as well. Some suggestions could be the following:

(a) A much greater sample is required in order to compare and confirm assumptions and research findings about Cyber bullying in Greece

(b) Cyber bullying victims and bullies relations should be further explored

(c) Parenting styles and how they are related to cyber bullying should be investigated in more detail and from different perspectives

(d) Age and cyber bullying is a factor that calls for further investigation as well, with an emphasis on adolescents, as evidence from national cyber crime units all over the world has shown that more and more adolescents are cyber bullied every day

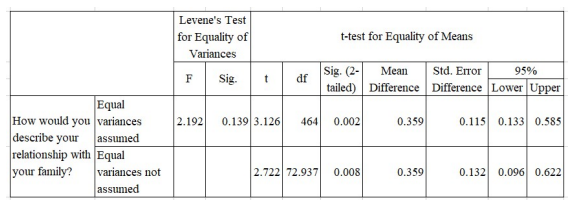

Figure 10. Independent Samples Test a) A much greater sample is required in order to compare and confirm assumptions and research findings about Cyber bullying in Greece. b) Cyber bullying victims and bullies relations should be further explored. c) Parenting styles and how they are related to cyber bullying should be investigated in more detail and from different perspectives. d) Age and cyber bullying is a factor that calls for further investigation as well, with an emphasis on adolescents, as evidence from national cyber crime units all over the world has shown that more and more adolescents are cyber bullied every day.

\section{References}

[1] I. Whitney, P.K. Smith, Educational research 35, 3 (1993)

[2] D. Olweus, European journal of psychology of education 12, 495 (1997)

[3] M. Franek, Educational Leadership 63, 39 (2005)

[4] D. Olweus, British Journal of Educational Psychology (1996)

[5] D. Olweus, Bully/victim problems in school (London: Taylor and Francis, 2003)

[6] P.K. Smith, J. Mahdavi, M. Carvalho, N. Tippett, Research Brief No. RBX03-06. London: DfES (2006)

[7] K.S. Berger, Developmental review 27, 90 (2007)

[8] F. Mishna, M. Saini, S. Solomon, Children and Youth Services Review 31, 1222 (2009)

[9] K. Subrahmanyam, P. Greenfield, The future of children pp. 119-146 (2008)

[10] C.S. Bhat, Journal of Psychologists and Counsellors in Schools 18, 53 (2008)

[11] E.M. Kraft, J. Wang, International Journal of Cyber Criminology 3 (2009)

[12] T. Aricak, S. Siyahhan, A. Uzunhasanoglu, S. Saribeyoglu, S. Ciplak, N. Yilmaz, C. Memmedov, Cyberpsychology \& behavior 11, 253 (2008)

[13] F. Dehue, C. Bolman, T. Vollink, M. Pouwelse, Journal of cybertherapy \& rehabilitation 5, 25 (2012)

[14] M.L. Ybarra, K.J. Mitchell, Journal of adolescence 27, 319 (2004)

[15] J. Wang, R.J. Iannotti, T.R. Nansel, Journal of Adolescent health 45, 368 (2009)

[16] S. Duman, G. Margolin, Journal of Clinical Child and Adolescent Psychology 36, 42 (2007)

[17] J.F. Knutson, D.S. DeGarmo, J.B. Reid, Aggressive behavior 30, 187 (2004)

[18] C.A. Mazefsky, A.D. Farrell, Journal of child and family studies 14, 71 (2005)

[19] D. Pontzer, Journal of Family Violence 25, 259 (2010)

[20] D. Bacchini, M. Concetta Miranda, G. Affuso, Journal of interpersonal violence 26, 269 (2011)

[21] S.A. Brown, D.H. Arnold, J. Dobbs, G.L. Doctoroff, Early Childhood Research Quarterly 22, 147 (2007)

[22] L. Demetriou, P. Christodoulides, The cyprus review 23, 81 (2011) 
[23] K. Getachew, M. Sintayehu, Ethiopian Journal of Education and sciences 2, 51 (2007)

[24] K. Luyckx, E.A. Tildesley, B. Soenens, J.A. Andrews, S.E. Hampson, M. Peterson, B. Duriez, Journal of Clinical Child \& Adolescent Psychology 40, 468 (2011)

[25] E. Flouri, A. Buchanan, Aggressive Behavior: Official Journal of the International Society for Research on Aggression 28, 126 (2002)

[26] S.N. Georgiou, Social Psychology of Education 11, 213 (2008)

[27] S. Ok, S. Aslan, Procedia-social and behavioral sciences 5, 536 (2010)

[28] M.K. Demaray, C.K. Malecki, School Psychology Review 32, 471 (2003)

[29] P.K. Smith, R. Myron-Wilson, Clinical Child Psychology and Psychiatry 3, 405 (1998)

[30] V. Stevens, I. De Bourdeaudhuij, P. Van Oost, Journal of youth and Adolescence 31, 419 (2002)

[31] C. Spera, Educational psychology review 17, 125 (2005)

[32] D. Baumrind, The journal of early adolescence 11, $56(1991)$

[33] Y.C. Wong, Journal of Technology in Human Services 28, 252 (2010)

[34] C.P. Barlett, D.A. Gentile, C. Chew, Psychology of Popular Media Culture 5, 171 (2016)
[35] C.P. Barlett, Psychology of Popular Media Culture 4, 70 (2015)

[36] M.J. Moore, T. Nakano, A. Enomoto, T. Suda, Computers in Human Behavior 28, 861 (2012)

[37] A.G. Dempsey, M.L. Sulkowski, J. Dempsey, E.A. Storch, Cyberpsychology, Behavior, and Social Networking 14, 297 (2011)

[38] Y. yin Huang, C. Chou, Computers in Human Behavior 26, 1581 (2010), online Interactivity: Role of Technology in Behavior Change

[39] M.L. Ybarra, M. Diener-West, P.J. Leaf, Journal of Adolescent Health 41, S42 (2007), youth Violence and Electronic Media: Similar Behaviors, Different Venues?

[40] F. Dehue, C. Bolman, T. Völlink, M. Pouwelse, International Journal of Stress Management 19, 175 (2012)

[41] J.W. Patchin, S. Hinduja, Youth violence and juvenile justice 4, 148 (2006)

[42] R. Slonje, P.K. Smith, A. Frisén, Computers in human behavior 29, 26 (2013)

[43] E. Blokland, R.C. Engels, C. Finkenauer, Aggressive behavior 27, 216 (2001)

[44] R. Likert, Archives of psychology (1932)

[45] R.M. Kowalski, S.P. Limber, P.W. Agatston, Cyberbullying: Bullying in the digital age (John Wiley \& Sons, 2012) 